\title{
Development of pedotransfer functions for Brazilian soils
}

\section{Desenvolvimento de funções hidropedológicas para solos brasileiros}

\author{
Willames de Albuquerque Soares ${ }^{1 *}$, Marco Aurelio Calixto Ribeiro de Holanda ${ }^{2}$, Diogo Botelho
} Corrêa de Oliveira ${ }^{2}$

\begin{abstract}
Pedotransfer Functions (PFT's) have several applications in the agri-environmental field, hydrodynamically characterizing soils in a less costly and more accessible way. The work proposed to develop equations that characterized Brazilian tropical soils through numerical validations available in the HYBRAS database, comparing them with others available in the literature. To analyze the performance of the proposed methods, we investigated the classical hydrodynamic parameters. The nonlinear equations obtained the best modeling, followed by the linear model and two others. When compared to the literature, the PTFs developed in this study proved to be more effective in estimating all the hydrodynamic parameters evaluated, especially those developed from multiple nonlinear regressions. However, its use in the Plinthossols, Luvisols, and Vertisols classes is not recommended since they do not belong to the database. It is also not recommended to use PTF to estimate: i) the saturated volumetric humidity in silty soils; ii) the residual volumetric humidity for soils of the textural classes Clay and Loam; iii) the parameter $\alpha$ in silty clay Loam, clay Loam, and silty Loam soils; and iv) the parameter $\mathrm{n}$ of Loam class soils.
\end{abstract}

Palavras-chave: Adequate performance; Tropical soils; Soil texture.

\section{RESUMO}

As Funções de Pedotransferência (PFT’s) possuem diversas aplicações no meio agroambiental, caracterizando hidrodinamicamente os solos de forma menos onerosa e mais acessível. O trabalho propôs desenvolver equações que caracterizaram solos tropicais brasileiros, por meio de validações numéricas disponíveis no banco de dados da HYBRAS, analisando os parâmetros hidrodinâmicos clássicos. Quando comparadas as existentes na literatura, as PTFs desenvolvidas neste estudo mostraram-se mais eficazes na estimativa de todos os parâmetros hidrodinâmicos avaliados, sobretudo as desenvolvidas a partir de regressões múltiplas não lineares. Apesar de não se recomendar sua utilização nos solos pertencentes as classes Plintossolos, Luvissolos e Vertissolos por não pertencerem ao banco de dados. Também não se recomenda o uso da PTF para estimar: i) a umidade volumétrica saturada em solos siltosos; ii) a umidade volumétrica residual para solos das classes texturais Argila e Franco; iii) o parâmetro $\alpha$ em solos Franco argilo siltosos, Franco argilosos e Franco siltosos; e iv) o parâmetro n dos solos da classe Franco.

Keywords: Adequação de equações; Solos tropicais; Textura do solo.

\footnotetext{
${ }^{1}$ University of Pernambuco.

*E-mail: was@poli.br

${ }^{2}$ Federal University of Pernambuco
} 


\section{INTRODUCTION}

The hydrodynamic properties of the soil are essential information in many fields of work and agri-environmental research. They are necessary in the establishment of strategies for agronomic adaptation to climate change and for the quantification of economic and environmental impacts, which may occur due to different soil management alternatives (VENTRELLA et al., 2019; MANICI et al., 2019; CASTELLINI et al., 2020).

In the last three decades, pedotransfer functions (PTF) have been widely used to estimate the hydrodynamic properties of the soil. They relate easily measurable soil data (such as texture, percentages of sand, silt, and clay), apparent density, organic matter or organic carbon, and/or other quantities routinely surveyed with hydraulic parameters. That is essential to elaborate the hydraulic conductivity and water retention curves in the soil (Van DEN BERG et al., 1997; RIBEIRO et al., 2018).

Most PFTs, which are available in the specialized literature, were developed and applied to temperate soils, especially when compared to those developed for tropical soils. However, several studies highlight that tropical soils have different hydrodynamic properties than soils in temperate regions due to differences in mineralogy and weathering history. Consequently, PTFs from data on temperate soils have limitations when applied to tropical soils; even so, they are used worldwide, mainly for global climate modeling (TOMASELLA et al., 2000).

In Brazil, the following studies stand out: Tomasella et al. (2000), who used information from a database, with 517 horizons from various regions; Barros et al. (2013), who developed PTFs from a set of 786 samples of data representative of the soils of Northeastern Brazil; and Medrado and Lima (2014), who developed PTF based on data from the cerrado. These PTFs were developed in order to estimate the parameters of van Genuchten's equation (1980).

The reduced amount of PTFs for tropical soils is due to the lack of measures, in sito, of the hydrodynamic and pedological properties on a large scale. For Brazilian soils, few databases are available probably due to the high costs. It is worth mentioning that composing a database representative for all Brazilian soils is a task that requires a lot of effort and time. Brazil is a continental country, with varied atmospheric conditions and soils. 
Only two free Brazilian databases were found in the literature: the Brazilian Soil Information System (BDSolos), produced by the Brazilian Agricultural Research Corporation (EMBRAPA); and the Hydrophysical database for Brazilian Soils (HYBRAS), develoepd by the Hydrology Department of the Brazilian Geological Survey (CPRM). HYBRAS has a total of 1075 samples referring to 445 soil profiles from 15 Brazilian states. Its main objective is to encourage the creation of PTFs for Brazilian soils, providing soil and hydraulic properties (OTTONI et al., 2018).

Thus, the objective was (i) to develop pedotransfer equations to estimate the parameters of the models proposed by van Genuchten (1980) through multiple regressions from the information available in the HYBRAS database and (ii) to compare the performance with other PTFs in the literature.

\section{MATERIALS AND METHODS}

\section{Description of the dataset}

The physical characteristics of the soils were obtained from the HYBRAS database, where the determination methods are described for each available soil property. Unfortunately, this database does not have a good representation of sandy soils, with just over $4 \%$ of the samples available there. The same is true for silty soils. On the other hand, there is a slight predominance of clay soils.

Adding the classes Silty Loam, Silty, Silty Clay Loam, and Silty Clay, there are only 50 samples, which corresponds to $4.65 \%$ of the total. The textural class Clay has a predominance, with approximately one quarter of the samples. The classes Loam, Sandy clay loam, and High clay content correspond to between $10 \%$ and $20 \%$ of the samples.

Soils with a high content of organic matter $(>6 \%)$ and low bulk density $(<0.8$ $\mathrm{gcm}^{-3}$ ) are also underrepresented in HYBRAS. This information is important since knowing the composition of the samples included in the study leads to greater reliability in the PFT estimates.

In this study, the soils available at HYBRAS were randomly divided into two groups. The first, with $75 \%$ of the data, was used in the development (CD) of the PTFs while the second was used in the validation of the developed equations (CV). 


\section{Pedotransfer functions used in the comparison}

Barros et al. (2013) developed some PTFs to estimate the parameters of the model for soil water retention curves proposed by van Genuchten (1980). For this, they used data from 786 Brazilian soil retention curves, mainly from the Northeast Region. Data was divided into two data sets: $85 \%$, for the development of PTFs; and 15\%, for testing and validation, considered as independent data.

The authors developed pedotransfer functions of a general nature, for all soils, and specific to some soil classes (Argisols, Latosols, Neossols and Planossols), using multiple regression techniques. Two types of PTFs were created, with 4 and with 2 input parameters. The first used the soil density and the contents of sand, clay, and organic matter; the second, only sand and clay contents.

These same authors observed that the prediction for the retention curve, by the equation composed of only 2 input parameters, was relatively weak for all parameters, except for the content $\theta_{r}$. The equation with four parameters improved the estimate only for parameter $\alpha$. The performance of the estimates by soil class, on the other hand, did not improve, compared to the general equation.

Medrado and Lima (2014) created a database containing the physical properties of tropical soils in the Brazilian cerrado, with a total of 413 profiles with varying depths, totaling 1401 soil samples. This soil database is quite representative for the region. From this information, they developed PTFs to determine the parameters of van Genuchten's equation (1980). The input data for these equations are density; total soil porosity; clay, sand, silt, and organic matter percentages. To assess the efficiency and performance of the proposed models, the authors compare their results with those obtained by the PTF proposed by Tomasella et al. (2000). The result reaches $70 \%$ for the database generated in 2014.

\section{Development of new pedotransfer functions}

The pedotransfer functions was developed by parameters: by adopting a conceptual model for the soil water retention curve, its use in modeling is possible. The soil water retention curve was proposed by van Genuchten (1980), Equation 1.

$$
\theta=\theta_{r}+\frac{\theta_{S}-\theta_{r}}{\left(1+|\alpha h|^{n}\right)^{1-\frac{2}{n}}}
$$


With $\theta_{r}\left(\mathrm{~cm}^{3} \mathrm{~cm}^{-3}\right)$ and $\theta_{s}\left(\mathrm{~cm}^{3} \mathrm{~cm}^{-3}\right)$ as the residual and saturated volumetric humidity, respectively; $h(\mathrm{~cm})$ the soil matrix potential e $\alpha\left(\mathrm{cm}^{-1}\right)$ and $n(-)$ curve shape parameters.

In this case, PTFs were developed using multiple linear and non-linear regressions. For each dependent parameter to be estimated, $Y \in\left\{\theta_{r}, \theta_{s}, \alpha, n\right\}$, linear and non-linear functions were formulated, based on each of the input data (independent), $X \in\left\{\right.$ sand (Are), silt (Sil), clay (Arg), apparent soil density (Ds), real density $\left(\rho_{p}\right)$, porosity $(\phi)$, organic matter $\left(M_{\text {org }}\right)$, organic carbon $\left.\left(C_{\text {org }}\right)\right\}$ available at HYBRAS, their coefficients were determined for optimization.

After determining the coefficients, adequacy was observed through its probability of significance $(p-$ value $)$. The attribute with the worst fit was eliminated and new coefficients were determined. This procedure was repeated until all attributes obtained a good fit $(p-$ value $<0,05)$.

\section{Evaluation of pedotransfer functions}

Two sets of statistical parameters were created. The first, which was used in the development of PTFs, served to legitimize the adjustment of the regression coefficients, formed by the standard error of the regression $\left(S_{x}\right)$ and the adjusted determination coefficient $\left(R_{a d j}^{2}\right)$.

In multiple regression, the addition of independent variables makes the regression equation less precise and the multiple regression coefficient $R^{2}$ does not reflect this fact. It occurs because its denominator (sum of total squares) remains constant, and its numerator can only increase or remain constant. In other words, any decrease in accuracy does not result in a $R^{2}$ lower. To contain this failure, it is necessary to consider the degrees of freedom adjusting the determination coefficient $R_{a d j}^{2}$ ). The $S_{x}$ provides important information that complements $R_{a d j}^{2}$. It represents the average distance over which the estimated values are from the regression line. It indicates how much the regression model is wrong when using the independent variables: the lower its value, the better the regression.

The second group was used to analyze the performance of the developed PTFs, when comparing them to the literature. It is formed by the following statistical parameters: the mean squared error $(M S E)$, the modeling efficiency $(M E)$, the residual mass coefficient $(R M C)$, the deviation ratio $(R D)$ and the error module (|Erro|), expressed by Equations 2 - 6: 


$$
\begin{aligned}
& M S E=\frac{100 \sqrt{\frac{\sum_{i=1}^{N}\left(T_{i}-M_{i}\right)^{2}}{N}}}{\bar{M}} \\
& M E=\frac{\sum_{i=1}^{N}\left(M_{i}-\bar{M}\right)^{2}-\sum_{i=1}^{N}\left(T_{i}-\bar{M}\right)^{2}}{\sum_{i=1}^{N}\left(M_{i}-\bar{M}\right)^{2}} \\
& R M C=\frac{\sum_{i=1}^{N} M_{i}-\sum_{i=1}^{N} T_{i}}{\sum_{i=1}^{N} M_{i}} \\
& R D=\frac{\sum_{i=1}^{N}\left(M_{i}-\bar{M}\right)^{2}}{\sum_{i=1}^{N}\left(T_{i}-\bar{M}\right)^{2}} \\
& \mid \text { Erro }=\sqrt{\left(M_{i}-T_{i}\right)^{2}}
\end{aligned}
$$

With $T_{i}$ as the simulated values, $M_{i}$ the measured values, $\bar{M}$ the average of the measured values and $N$ the number of observations.

The MSE indicates the degree of deviation between the experimental determinations and the values calculated by the corresponding theoretical model. It is expressed as a percentage and tends to zero when the estimated and theoretical values tend to be equal. This test provides information that is easy to understand in the performance of the models. It also allows comparing, term by term, the actual deviation between the calculated value and the measured value. The $M E$ evaluates how much the models used generate results close to those found experimentally; its optimal value tends to one. The $R M C$ indicates whether the model tends to overestimate $(R M C<0)$ or underestimate $(R M C>0)$ the measured values. The expected value for the $R M C$ tends to zero.

The $R D$ describes the ratio between the spread of the experimental determinations and the spread of the values calculated by the corresponding theoretical model. It tends to 1 (one) when the measured and estimated values are consistent. As its name implies, the $\mid$ Erro $\mid$ describes error in estimating the parameters. Its ideal value tends towards zero and is not influenced by the sign of the values.

\section{RESULTS}

\section{Preliminary analysis of the dataset}

The 1075 samples, available at HYBRAS, were divided into two collections: one with $75 \%$ of the data, used for the development of PTFs, and the other with $25 \%$, used in 
its validation (Table 1). In addition, the distribution of soils between the two sets (CD and $\mathrm{CV}$ ) was done at random.

Table 1 - Quantities of samples used in the development and validation of PTFs for dependent parameters.

\begin{tabular}{lccc}
\hline Parameter & Development & Validation & Total \\
\hline$\theta_{s}$ & 590 & 196 & 786 \\
$\theta_{r}$ & 673 & 224 & 897 \\
$\alpha$ & 797 & 266 & 1063 \\
$n$ & 685 & 246 & 931 \\
\hline
\end{tabular}

In Figure 1, we can see the distribution of the soil textural fractions (percentage), which formed the CD and CV used in the construction and evaluation of the PTF that estimate the four parameters.

For $\theta_{s}$, both collections presented very similar percentage values. The differences between the maximum values of clay, silt, and sand were approximately $1 \%, 3 \%$, and $4 \%$, respectively. As for $\theta_{r}$, the $\mathrm{CD}$ and $\mathrm{CV}$ samples have similar clay, silt, and sand values in all quartiles and in the minimum values. However, there is a slight difference between the maximum values of clay and silt, which are 96 and 63.3\%, in the DC; and 91 and $54.4 \%$ in the $\mathrm{CV}$. It is expected that this small difference will not produce extrapolation errors.

The soil samples that comprised the $\mathrm{CD}$ and the $\mathrm{CV}$, used in the estimation of $\alpha$ and $\mathrm{n}$, have similar percentages for all textural fractions of the soils in the first quartiles and in the minimum values. However, for $\alpha$ there is a slight difference between the values of silt in the second and third quartiles as well as in the maximum values of the clay percentage. In these three cases, the values present on the $\mathrm{CD}$ are approximately $3 \%$ higher. For $n$, there is a slight difference between the values of the second quartiles of clay; the values of the third quartiles of sand; and the maximum values of clay and silt. In all cases, the difference is less than $4 \%$.

The proportions of the textural classes, present in the $\mathrm{CD}$ and $\mathrm{CV}$, for $\theta_{s}$, were relatively maintained. Only two textural classes showed a maximum percentage difference greater than $2 \%$. The greatest differences in proportionality occurred in the Clay loam and High clay content classes, which showed discrepancies of 5\% and $13 \%$, respectively, of the total $\mathrm{CD}$; in the $\mathrm{CV}$, values corresponded to $2 \%$ and $16 \%$. The Silty 
loam class appears only on the CD. This is due to the small number of samples in this class (only 2) and the randomness of the group composition.

Figure 1 - Box diagram of the percentages of clay, silt and sand, used in the development and validation of PTF for: A $\theta_{s}, \mathrm{~B} \theta_{r}, \mathrm{C} \alpha$ e D $n$.
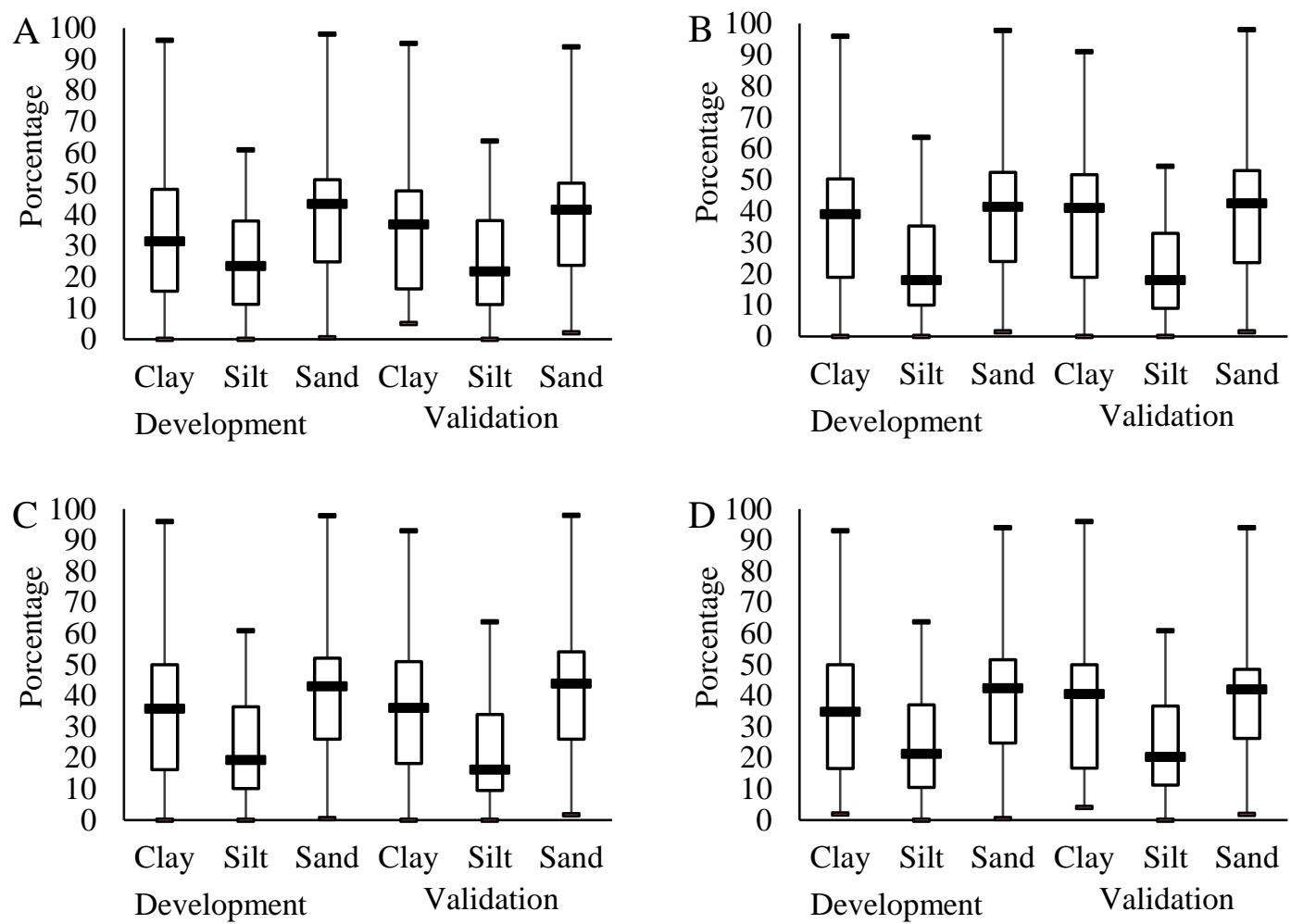

For $\theta_{r}$, the proportions of the textural classes present in the $\mathrm{CD}$ and $\mathrm{CV}$ were maintained. Only the High content clay class showed significant differences in proportions, with values of 13 and $16 \%$, respectively, in the CD and CV. In all others, the maximum percentage difference was less than $2 \%$. The Silty loam class does not appear in any of the sets. This is due to the small number (2) of samples in this class.

As for $\alpha$, the $\mathrm{CD}$ and $\mathrm{CV}$ showed a great difference in the representativeness of the textural class Clay, with values of $27 \%$ and $34 \%$, respectively. The two groups also showed differences in the soils of the Clay loam and Loam textural classes, with a 5\% higher appearance on the $\mathrm{CD}$. In the other textural classes, proportionality is maintained, with a maximum difference of less than $2 \%$.

For $n$, in eight textural classes, proportionality is maintained (sand, loam sand, silty clay, sandy loam, silty slay loam, clay loam, silt loam, loam), with a maximum percentage difference of less than $2 \%$. The greatest proportionality differences occur in 
the classes Clay and Sandy clay loam (which present percentage differences of 5\%) as well as in the sandy clay class (difference of 3\%).

\section{Development of new pedotransfer functions}

For the four hydrodynamic parameters, PTFs were developed based on linear regressions (Equations 7-10) and nonlinear (Equations 11-14), shown in Table 2. The input parameters were: the apparent density, the real density, and soil porosity, in addition to the percentages of silt, clay, and sand.

Table 2 - PTFs developed to estimate the dependent parameters $\left(\theta_{s}, \theta_{r}, \alpha\right.$ and $\left.n\right)$

\begin{tabular}{|c|c|}
\hline \multicolumn{2}{|l|}{ Linear PTF (LI) } \\
\hline$\theta_{s}=0.6857 \mathrm{Arg}+0.2561 \mathrm{Are}+0.0987 D_{s}$ & (7) \\
\hline$\theta_{r}=0.1025 \mathrm{Sil}+0,2995 \mathrm{Arg}+0.0397 D_{s}$ & (8) \\
\hline$\alpha=\ln \left(2.5442 \mathrm{Sil}+2.1776 \mathrm{Arg}+1.7622 \mathrm{Are}-0.5210 D_{s}\right)$ & (9) \\
\hline$n=0.0294 \mathrm{Arg}+0.0275 \mathrm{Sil}+0.0338 \mathrm{Are}-1.6059 D_{s}+0.8669 \rho_{p}-3.7831 \phi$ & $(10)$ \\
\hline \multicolumn{2}{|l|}{ Non-Linear PTF (NL) } \\
\hline $\begin{array}{l}\theta_{s}=0.8544 \mathrm{Arg}-0.6613 \mathrm{Arg}^{2}+0.0034 \mathrm{Arg}^{-1}+0.4861 \text { Are }- \\
-0.3815 \mathrm{ArgAre}+0.2533 D_{s}-0.0790 D_{s}^{2}+0.1669 D_{s}^{-1}-0.3245 D_{s} \text { Are }\end{array}$ & $(11)$ \\
\hline$\theta_{r}=\ln \left(1.5084\right.$ Are +1.1076 Sil +1.0855 Arg -0.5298 Are $^{2}+0.3501$ Arg $\left.^{2}\right)$ & $(12)$ \\
\hline$\alpha=\ln (-33.067$ Are -90.111 Arg -32.680 Sil -3.369 Sil Are + & $(13)$ \\
\hline + 32.620 Sil Arg + 28.256 Arg Are $\left.+33.958 e^{\mathrm{Arg}}-0.5063 \mathrm{Arg} D_{s}\right)$ & \\
\hline$n=0.0460 \mathrm{Arg}+0.0433 \mathrm{Sil}+0.0412 \mathrm{Are}-5.7492 \phi-0.3338 D_{s}^{2}+$ & $(14)$ \\
\hline$+0.1144 \rho_{p}^{2}+3.7191 \phi^{2}-0.2544 \ln (\mathrm{Arg})-0.1441 \ln (\mathrm{Sil})$ & \\
\hline
\end{tabular}

The results from the present work along with Barros et al. (2013) and Medrado and Lima (2014) are shown in Table 3. In the development phase, the non-linear PTFs (NL) presented $R_{a d j}^{2}$ closer to one when compared to the values obtained by the linear PTFs (LI). The later was developed to estimate all hydrodynamic parameters with the exception of parameter $n$, where the performances were similar.

In the validation phase, the first place went to the NL PTFs, which presented the best performances for all parameters, with the lowest $M S E$ value. That indicates a lower degree of deviation. The $M E$ closer to one corroborates the use of PTFs instead of the 
average value of the measured values. In addition, they presented a slight underestimation of the measured values, with the lowest $R M C$.

Table 3 - Statistical parameters used in the development and validation for estimative of $\theta_{s}, \theta_{r}$, $\alpha$ and $n$ by: PTFs (LI), non-linear PTFs (NL), Barros et al. (2013) (BA), and Medrado and Lima (2014) (ML).

\begin{tabular}{|c|c|c|c|c|c|c|c|}
\hline \multirow[b]{2}{*}{$\begin{array}{l}\text { Dependent } \\
\text { Parameters }\end{array}$} & \multirow[b]{2}{*}{ PTF } & \multicolumn{2}{|c|}{ Development } & \multicolumn{4}{|c|}{ Validation } \\
\hline & & $R_{a d j}^{2}$ & $S_{x}$ & $\begin{array}{c}M S E \\
(\%)\end{array}$ & $M E$ & $R M C$ & $R D$ \\
\hline \multirow{4}{*}{$\theta_{s}$} & LI & 0.96 & 0.10 & 24.01 & -0.16 & 0.03 & 1.58 \\
\hline & NL & 0.99 & 0.05 & 10.64 & 0.77 & -0.00 & 1.37 \\
\hline & $\mathrm{BA}$ & --- & --- & 26.16 & -0.38 & 0.16 & 1.65 \\
\hline & ML & --- & --- & 75.54 & -10.52 & -0.71 & 0.08 \\
\hline \multirow{4}{*}{$\theta_{r}$} & LI & 0.90 & 0.06 & 30.55 & 0.50 & 0.01 & 2.39 \\
\hline & NL & 0.99 & 0.07 & 29.40 & 0.54 & 0.01 & 2.00 \\
\hline & $\mathrm{BA}$ & --- & --- & 37.61 & 0.25 & -0.05 & 0.68 \\
\hline & ML & --- & --- & 51.45 & -0.41 & 0.31 & 1.15 \\
\hline \multirow{4}{*}{$\alpha$} & LI & 0.88 & 0.50 & 118.13 & 0.09 & -0.08 & 4.02 \\
\hline & NL & 0.90 & 0.47 & 115.02 & 0.13 & -0.08 & 2.99 \\
\hline & $\mathrm{BA}$ & --- & --- & 130.45 & -0.12 & 0.23 & 7.08 \\
\hline & ML & --- & --- & 173.04 & -0.96 & -1.24 & 0.92 \\
\hline \multirow{4}{*}{$n$} & LI & 0.97 & 0.22 & 16.36 & 0.13 & 0.00 & 5.82 \\
\hline & $\mathrm{NL}$ & 0.98 & 0.21 & 15.82 & 0.16 & 0.00 & 3.43 \\
\hline & $\mathrm{BA}$ & --- & --- & 18.34 & -0.10 & -0.02 & 2.87 \\
\hline & ML & --- & --- & 22.88 & -0.72 & 0.03 & 1.28 \\
\hline
\end{tabular}

$R_{a d j}^{2}$ the adjusted coefficient of determination, $S_{x}$ the standard error, $M S E$ the mean squared error, $M E$ the modeling efficiency, $R M C$ the residual mass coefficient and $R D$ ratio of the deviations.

The second best performance was obtained by LI PTFs, which presented the second best values of MSE, ME and RMC, with a slight underestimation of the measured data. The third best performance was obtained by BA, which presented results close to those found by linear functions, with slightly lower performance. The PTF in ML, on the other hand, had the worst performance. However, it is noteworthy that to propose this equation, the authors used a data set composed only of samples from the Brazilian 
cerrado, instead of national territory. Figure 2 shows the error modules produced by the 4 PTFs.

For $\theta_{s}$, it is observed that when using the LI PTFs, the error can reach almost 0.60 $\mathrm{cm}^{3} \mathrm{~cm}^{-3}$, which would make the estimate totally unfeasible. However, it is important to note that, in $75 \%$ of the cases, this error is less than $0.13 \mathrm{~cm}^{3} \mathrm{~cm}^{-3}$, while $25 \%$ had errors below $0.04 \mathrm{~cm}^{3} \mathrm{~cm}^{-3}$. These numbers are quite different when using NL PTF. The maximum error was $0.17 \mathrm{~cm}^{3} \mathrm{~cm}^{-3}$ and in $75 \%$ of cases, the error is less than $0.07 \mathrm{~cm}^{3} \mathrm{~cm}^{-}$ 3. In addition, half of the estimates show errors of less than $0.4 \mathrm{~cm}^{3} \mathrm{~cm}^{-3}$. BA PTF presented values for error module similar to those found by linear regression.

However, the main differences are in the maximum error, which was $0.40 \mathrm{~cm}^{3} \mathrm{~cm}^{-}$ ${ }^{3}$, lower than that found by LI PTF. That result would make it more reliable. It should be noted that the error limit, for $75 \%$ of the data for BA PTF, is almost $0.16 \mathrm{~cm}^{3} \mathrm{~cm}^{-3}$, while that presented by linear PTF is less than $0.12 \mathrm{~cm}^{3} \mathrm{~cm}^{-3}$. The errors produced in ML PTF make its use unfeasible. Analyzing the error module for non-linear PTF, it is observed that in only ten soil samples (out of a total of 786) there was an error greater than 0.10 .

For $\theta_{r}$, the errors by LI and NL PTFs are similar. The maximum error is approximately $0.19 \mathrm{~cm}^{3} \mathrm{~cm}^{-3}$. In $75 \%$ of cases, this error is less than $0.06 \mathrm{~cm}^{3} \mathrm{~cm}^{-3}$ and in $25 \%$ of cases they are less than $0.02 \mathrm{~cm}^{3} \mathrm{~cm}^{-3}$. The PTF proposed by Barros et al. (2013) presented values of the error module similar to those found by the present work, with slightly higher values in the first three quartiles.

However, it should be noted that the maximum error was $0.17 \mathrm{~cm}^{3} \mathrm{~cm}^{-3}$, which is less than the results obtained by the LI and NL PTFs, corroborating its good performance. As shown in the statistical performance, the ML PTF produced errors when estimating the values of the parameters in samples for the CV. In $75 \%$ of cases, the error by both reached $0.1 \mathrm{~cm}^{3} \mathrm{~cm}^{-3}$. The maximum error was $0.35 \mathrm{~cm}^{3} \mathrm{~cm}^{-3}$. It is highlighted that in 57 of the 224 samples, this error was greater than $0.06 \mathrm{~cm}^{3} \mathrm{~cm}^{-3}$. From these, 14 had errors of less than $0.07 \mathrm{~cm}^{3} \mathrm{~cm}^{-3}$, while 10 errors are between $0.08 \mathrm{~cm} 3 \mathrm{~cm}-3$ and $0.09 \mathrm{~cm}^{3} \mathrm{~cm}^{-3}$. In the CV group, there is a predominance of the textural classes Clay (39\%) and Loam (26\%). These higher percentages not only occur because of their representativeness in HYBRAS, but also indicate an adaptation, not very effective, of the PTF for these textural soil classes.

The module of errors found in the $\alpha$, estimates, are shown in Figure 2C. It is observed that when using both LI and NL PTFs, the errors are similar. The maximum 
errors were 0.97 and 0.85 , respectively. For both, in $75 \%$ of the cases, this error is less than 0.34 ; in $25 \%$ of the cases, the values show errors of less than 0.09 . For BA PTF, it presented error module similar to those found by the LI and NL PTFs, with better results in the first three quartiles.

Figure 2 - Box plot of the error module determined from the estimates of A $\theta_{\mathrm{s}}$, B $\theta_{\mathrm{r}}$, de $\mathrm{C} \alpha$ and D $n$ by the equations: linear PTFs (LI), non-linear PTFs (NL), Barros et al. (2013) (BA), and Medrado and Lima (2014) (ML).
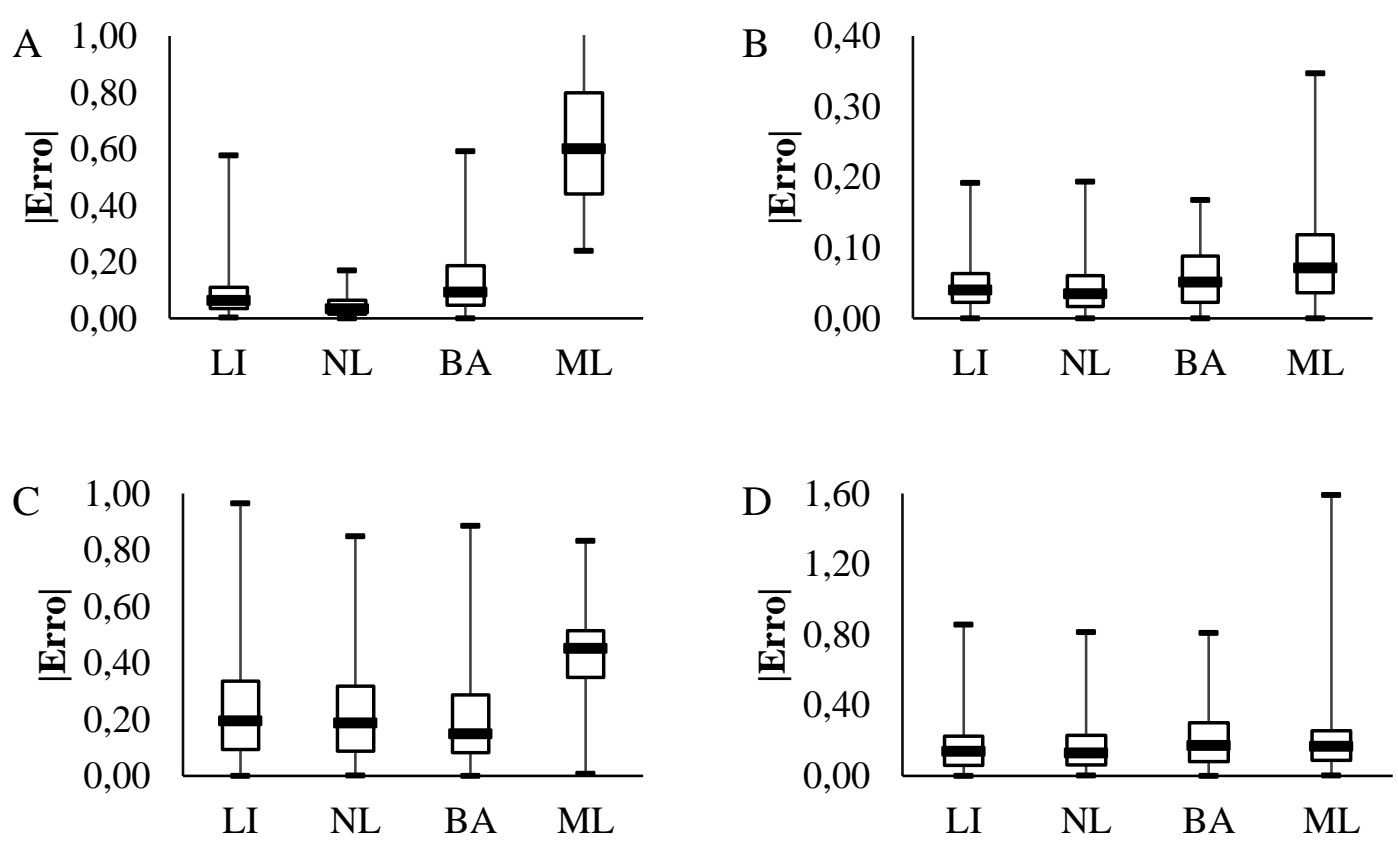

However, the maximum error found was 0.93 , slightly higher than the errors in the proposed PTFs, corroborating its good performance. As shown in the statistical performance, ML PTF presented the least satisfactory results. Analyzing the error on estimating $\alpha$ from NL PTF, it is highlighted that 64 of the 266 samples, presented an error greater than 0.32 .

In addition, in the $\mathrm{CV}$, ten of the twelve textural classes of the soil are present, with a predominance of: clay (33\%), high clay content (19\%), and sandy loam (14\%). These higher percentages are the consequence of the greater representativeness of these classes within the CV group. Because they have a small percentage in this group, the silty clay loam, clay loam, and silty loam classes have low representativeness in the CV, indicating that NL PTF is not very effective in estimating $\alpha$ in those soils.

For $n$, when using the LI and NL PTFs, it is noted that the errors are similar, with peaks of 0.86 and 0.81 , respectively. For both, in $75 \%$ of the cases, this error is less than 
0.23 while in $25 \%$ of the cases, the values show errors below 0.06 . BA PTF performed well, as $25 \%$ of the cases had a maximum error of 0.13 ; in $75 \%$ of the cases, the error reached 0.37 . The maximum error value was 0.67. ML PTF, on the other hand, presented satisfactory results in the first three quartiles, where the error in $75 \%$ of the cases reaches a maximum of 0.30 . The maximum error was greater than 1.5.

Analyzing the estimate of $n$ by PTF NL, it was observed that 58 of the 246 samples had errors that exceeded the value of 0.23 . It should be noted that there are elements from seven of the twelve soil textural classes in the $\mathrm{CV}$, with a predominance of Loam, with $31 \%$. This higher percentage of free soils is not only a consequence of the greater representativeness of this class within HYBRAS, but also indicates that NL PTF has low efficiency in estimating $\mathrm{n}$ in those soils textural.

\section{CONCLUSIONS}

Pedotransfer functions (PTFs) were developed using multiple linear and nonlinear regressions to estimate the parameters of the soil water retention curves proposed by van Genuchten (1980), using the HYBRAS database.

Comparing the literature on this matter, the PTFs developed in this study proved to be more effective in estimating all the hydrodynamic parameters evaluated, especially those developed from multiple nonlinear regressions. However, it is not recommended to use them in soils belonging to the Plinthosols, Luvisols, and Vertisols classes because they are not represented in HYBRAS.

It is also not recommended to use PTF to estimate: i) the saturated volumetric humidity in silty soils; ii) the residual volumetric humidity for soils of the textural classes Clay and Loam; iii) the parameter $\alpha$ in silty clay Loam, clay Loam, and silty Loam soils; and iv) the parameter $\mathrm{n}$ of Loam class soils.

\section{ACKNOWLEDGMENTS}

The present work had support from the Coordenação de Aperfeiçoamento de Pessoal de Nível Superior (CAPES, Coordination for the Improvement of Higher Education Personnel). 


\section{REFERENCES}

BARROS, A. H. C., LIER, Q. de J. V., MAIA, A. de H. N., SCARPARE, F. V. Pedotransfer Functions to Estimate Water Retention Parameters of Soils in Northeastern Brazil. Revista Brasileira de Ciências do Solo, Viçosa. v. 37, p. 379-391, 2013.

BROOKS, R. H.; COREY, A. T. Hydraulic properties of porous media. Hydrology Paper, n.3, Fort Collins: Colorado State University, 1964. 27p.

CASTEllini, M.; STEllaCCI, A. M.; MASTRANGElO, M.; CAPUTO, F.; MANICI, L. M. Estimating the soil hydraulic functions of some olive orchards: Soil management implications for water saving in soils of Salento península (southern Italy). Agronomy, v. 10, n. 2, p. 1-17, 2020. Doi: 10.3390/agronomy 10020177

MANICI, L. M.; CASTELLINI, M.; CAPUTO, F. Soil-inhabiting fungi can integrate soil physical indicators in multivariate analysis of Mediterranean agroecosystem dominated by old olive groves. Ecological Indicators. v. 106, p. 1-11, 2019. https://doi.org/10.1016/j.ecolind.2019.105490

RIBEIRO, B. T., COSTA, A. M., SILVA, B. M., FRANCO, F. O., BORGES, C. S. Assessing pedotransfer functions to estimate the soil water retention. Bioscience Journal, v. 34, n. 1, p. 177-188, 2018. Doi: 10.14393/BJ-v34n6a2018-42371

TOMASELLA, J.; HODNETT, M. G.; ROSSATO, L. Pedotransfer functions for the estimation of soil water retention in Brazilians soils. Soil Science Society of America Journal, v. 64, p.327- 338, 2000. Doi: 10.2136/sssaj2000.641327x

VAN DEN BERG, M.; KLAMT, E.; VAN REEUWIJK, L. P.; SOMBROEK, W. G. Pedotransfer functions for the estimation of moisture retention characteristics of Ferralsols and related soils. Geoderma, v. 78, p.161-180, 1997. Doi: 10.1016/S00167061(97)00045-1

VAN GENUCHTEN, M. Th. A closed-form equation for predicting the hydraulic conductivity of unsaturated soils. Soil Science Society of American Journal, v.44, p. 892-898, 1980.

VENTRELLA, D.; CASTELliNI, M.; DI PRIMA, S.; GAROFALO, P.; LASSABATĖRE, L. Assessment of the Physically-Based Hydrus-1D Model for Simulating the Water Fluxes of a Mediterranean Cropping System. Water, v. 11, n. 8 p.1-19, 2019. Doi: 10.3390/w11081657

MEDRADO, E.; LIMA, J. E. F. M. Development of pedotransfer functions for estimating water retention curve for tropical soils of Brazilian savanna. Goderma Regional, v. 1, p. 55-66, 2014. Doi: 10.1016/j.geodrs.2014.08.003 
OTTONI, M. V.; OTTONI FILHO, T. B.; SCHAAP, M. G.; LOPES-ASSAD, M. L. R. C.; ROTUNNO FILHO, O. C. Hydrophysical Database for BrazilianSoils (HYBRAS) and Pedotransfer Functions for Water Retention. Vadose Zone Journal, v. 17, p.1-17. 2018. Doi: $10.2136 / v z j 2017.05 .0095$

Recebido em: 05/01/2022

Aprovado em: 08/02/2022

Publicado em: 11/02/2022 